\title{
Relative Susceptibility of Selected Apple Cultivars to Colletotrichum acutatum
}

\author{
A. R. Biggs, Professor, West Virginia University, Kearneysville Tree Fruit Research and Education Center, P.O. Box \\ 609, Kearneysville, and Stephen S. Miller, Research Horticulturist, USDA-ARS, Appalachian Fruit Research Sta- \\ tion, 45 Wiltshire Rd., Kearneysville 25430
}

\begin{abstract}
Biggs, A. R., and Miller, S. S. 2001. Relative susceptibility of selected apple cultivars to Colletotrichum acutatum. Plant Dis. 85:657-660.

Eighteen apple cultivars were tested in the field and laboratory for their relative susceptibility to one of the bitter rot pathogens, Colletotrichum acutatum. Fruit were inoculated in the field at 3 to 4 weeks preharvest with cheesecloth strips soaked in a conidia suspension. In the laboratory, detached fruit were inoculated using a conidia suspension in capped, sterile microcentrifuge tubes attached to the fruit surface with modeling clay. The same fruit as above also were inoculated over a wound on the side opposite the nonwounded inoculation. Fruit were tested for relative susceptibility to the fungus with five criteria: disease incidence and severity of attached fruit in the field, disease incidence and severity of detached fruit in laboratory inoculations of nonwounded fruit, and disease severity in laboratory inoculations of wounded fruit. Relative cultivar ranks from field tests were not reproducible in the 2 years studied, whereas laboratory tests showed moderate reproducibility with nonparametric rank correlation tests. Based on the laboratory data from 2 years of study, cultivars were classified into four relative-susceptibility groups: most susceptible: Pristine, Honeycrisp, and Ginger Gold; highly susceptible Yataka, Sansa, Arlet, and Enterprise; moderately susceptible: Sunrise, Golden Supreme, PioneerMac, GoldRush, Golden Delicious, and Creston; and least susceptible: Fuji. Compared to previous cultivar rankings, the results of the present study indicate that new apple cultivars from the first NE-183 planting show no improvement in resistance to C. acutatum.
\end{abstract}

Additional keywords: bitter rot

Bitter rot, caused by the fungi Colletotrichum gloeosporioides and C. acutatum, is an important disease in the mid-Atlantic and southern areas of the United States $(5,9)$. Disease outbreaks can occur rapidly and losses can be severe, especially under prolonged warm, wet weather conditions (1). Several host species can be affected, including peach, nectarine, and grape (2). The primary hosts, however, are apple and pear.

Field evaluations for the incidence of rot diseases in apple can be difficult because of the similarity of symptoms caused by the various pathogens (e.g., C. acutatum, C. gloeosporioides, Botryosphaeria dothidea, B. obtusa). Determination of the causal organisms from natural infections by isolation are labor-intensive and may yield multiple rot pathogens and contaminating organisms. Laboratory or field inoculation studies under controlled conditions allow for positive identification of

Corresponding author: A. R. Biggs

E-mail: abiggs2@wvu.edu

Accepted for publication 1 March 2001.

This is Scientific Article No. 2780 of the West Virginia Agricultural and Forestry Experiment Station.

Publication no. D-2001-0419-02R

(C) 2001 The American Phytopathological Society symptomology and characterization of the host-pathogen relationship.

The susceptibility ranking of various apple cultivars to diseases often depends on the plant breeder and a few test sites, or on observations by growers and/or nursery personnel in the field, rather than the results of systematic study. In 1994, a regional project was initiated to look at the performance of new apple cultivars in replicated trials under a wide range of climatic and edaphic conditions. The project (NE-183), entitled "Multidisciplinary Evaluation of New Apple Cultivars," has 26 cooperators in 18 states and two Canadian provinces. A primary objective of the NE-183 project is to evaluate horticultural qualities and pest susceptibility of new apple cultivars, strains, and advanced selections with commercial potential, and to determine the limitations and positive attributes of these cultivars. To date, researchers have documented the relative susceptibilities of the NE-183 apple cultivars to apple scab, powdery mildew, and cedar-apple rust $(4,6,10,12)$. No methods have been specified for the evaluation of rot diseases, including those caused by species of Botryosphaeria and Colletotrichum. The objectives of this study were to develop a test for relative susceptibility to rot pathogens, and to evaluate the relative susceptibility of apple cultivars to one of the bitter rot pathogens, C. acutatum.

\section{MATERIALS AND METHODS}

Test planting. The 23 apple cultivars selected for the NE-183 project were budded on M.9 337 rootstock. Trees were planted in north-south oriented rows in April 1995 at a spacing of $2.5 \mathrm{~m} \times 4.3 \mathrm{~m}$ with a mechanical tree planter. The design was a randomized complete block with 5 singletree plots per cultivar. Drive middles were planted with Kentucky-31 fescue, and a weed-free strip ( $1 \mathrm{~m}$ wide in $1995,2 \mathrm{~m}$ wide in the remaining years) was maintained in the tree row using paraquat plus oryzalin at recommended rates. After planting, a conduit stake secured to a single trellis wire at $2.1 \mathrm{~m}$ height was placed beside each tree and the tree's leader was tied to the stake. Minimal pruning was followed throughout this study, allowing trees to assume their natural form. All bloom was removed in the first season (1995). Trees were allowed to fruit after the first growing season and crop load was adjusted by hand when necessary to space fruit about $15 \mathrm{~cm}$ apart. Drip irrigation was installed in the summer of 1997 . The planting received no pesticide applications in 1995. Insecticides were applied from 1996 through 1999, as were fixed copper and streptomycin to suppress fire blight. Dodine, myclobutanil, fenarimol, and/or mancozeb were applied at recommended rates beginning 12 April and continuing through 21 May 1999 for early season scab control. No fungicides were applied after 21 May in 1998 or 1999. Eighteen cultivars (Table 1) were selected in the planting for field inoculation tests in 1998 and 1999. Temperature, relative humidity and leaf wetness were monitored with a 7-day recorder (Belfort Instruments, Baltimore, MD).

Fungal isolates. Colletotrichum acutatum was chosen for this research because it is the predominant bitter rot pathogen in West Virginia and northern Virginia (A. R. Biggs, unpublished). A representative fungal isolate (designated CaVA-1) was obtained from Dr. K. S. Yoder (Virginia Tech Agricultural Research and Extension Center, Winchester, VA), and was subcultured and maintained on potato dextrose agar in petri dishes. Dishes were subcultured weekly and maintained at $22^{\circ} \mathrm{C}$ during the periods in which experiments were conducted. Conidia were harvested from $7-$ day-old cultures in all studies by flooding the dishes with sterile, distilled water, scraping the plates with a rubber spatula, and then filtering the suspension through 
four layers of sterile cheesecloth. The desired concentrations of conidia were prepared by diluting the original suspensions, which had been counted with a hemacytometer.

Field experiments. Fruit were inoculated in the field at 3 to 4 weeks preharvest (Table 1), as determined by average ripening date and quality assessments, which included starch index, percent soluble solids and flesh firmness. Arbitrarily selected fruit were inoculated by dipping cheesecloth strips (about $2.5 \mathrm{~cm}$ wide and $15 \mathrm{~cm}$ long) into a suspension of $1 \times 10^{6}$ conidia $/ \mathrm{ml}$. The strips were applied around the circumference of the fruit, secured with a layer of plastic wrap and an outside layer of aluminum foil, both of which covered the fruit completely. The inoculum was removed after 7 days. Thirty-two fruit were inoculated per cultivar in three replications of eight fruit, and eight fruit were inoculated with sterile distilled water as a control. None of the control fruit developed bitter rot during the course of the study. The study was conducted over two growing seasons, 1998 and 1999.

Laboratory experiments. Fruit were picked at 2 to 3 weeks before their normal harvest date, brought to the laboratory, and washed with tap water. Fruit were inoculated with $1 \mathrm{ml}$ of a $1 \times 10^{5}$ conidia $/ \mathrm{ml}$ suspension in $1.5 \mathrm{ml}$ capped, sterile microcentrifuge tubes with the tapered end removed. Tubes were attached to the fruit surface with modeling clay, which provided a watertight seal and prevented leakage of the inoculum. Sharp edges of the cut end of the tubes had been trimmed to avoid injuring the fruit surface. The clay, tubes and inoculum were removed after 7 days at
$22 \pm 2^{\circ} \mathrm{C}$. Thirty-two fruit, including three replications of eight fruit, and eight fruit inoculated with sterile distilled water were used. None of the control fruit developed bitter rot during the observation period.

The same fruit also were inoculated over a wound on the side opposite the nonwounded inoculation. The wound was created with a device in which five insect pins were inserted through a cork stopper until they protruded $2 \mathrm{~mm}$ from the other side. The device was pressed once against the fruit surface. Inoculum was delivered to the wounds with the capped tubes as described above. The inoculum was removed after 7 days. The number of fruit, replications and control was the same as described previously. None of the wounded control fruit developed bitter rot. Five additional fruit of each cultivar were sampled for determination of flesh firmness and percent soluble solids. Flesh firmness was measured with a hand-held penetrometer (Effigi Inc., Italy) fitted with an 11-mm tip. Soluble solids were measured with a hand-held refractometer (Fisher Scientific, Pittsburgh, PA). The study was conducted over two growing seasons, 1998 and 1999.

Data collection and analysis. Fruit were rated for relative susceptibility to the fungus using these criteria: disease incidence and severity of attached fruit in the field; disease incidence and severity of detached fruit in laboratory inoculations of nonwounded fruit, and disease severity in laboratory inoculations of wounded fruit. Severity in the field was determined by rating the surface area affected using the following scale: $0=$ no lesions,; $1=1$ to $10 \% ; 2=11$ to $25 \% ; 3=26$ to $50 \% ; 4=51$ to $75 \% ; 5=76$ to $90 \%$, and $6=91$ to $100 \%$

Table 1. Cultivar, date of inoculation, and mean temperature for the 7-day period following inoculation for apple cultivars inoculated with Colletotrichum acutatum

\begin{tabular}{lccccc}
\hline & \multicolumn{2}{c}{$\mathbf{1 9 9 8}$} & & \multicolumn{2}{c}{$\mathbf{1 9 9 9}$} \\
\cline { 2 - 3 } \cline { 5 - 6 } Cultivar & Inoculation date & $\begin{array}{c}\text { Mean } \\
\text { temperature }\left({ }^{\mathbf{}} \mathbf{C}\right)\end{array}$ & Inoculation date & $\begin{array}{c}\text { Mean } \\
\text { temperature }\left({ }^{\circ} \mathbf{C}\right)\end{array}$ \\
\hline Pristine & 12 July & 25.1 & & 13 July & 24.5 \\
Sunrise & 14 July & 26.1 & & 17 July & 26.9 \\
Sansa & 20 July & 24.9 & & 27 July & 25.3 \\
Ginger Gold & 21 July & 24.6 & & 26 July & 25.7 \\
PioneerMac & 2 August & 24.9 & & 1 August & 22.8 \\
Arlet & 2 August & 23.3 & & 1 August & 22.8 \\
Senshu & 5 August & 25.1 & & 9 August & 23.0 \\
Golden Supreme & 10 August & 24.6 & & 14 August & 23.4 \\
Honeycrisp & 11 August & 24.3 & & 15 August & 22.7 \\
Golden Delicious & 23 August & 26.2 & & 30 August & 19.6 \\
NY75414 & 31 August & 22.9 & & 29 August & 19.7 \\
Creston & $-\mathrm{z}$ & - & & 28 August & 19.8 \\
Fortune & 1 September & 22.9 & & 28 August & 19.8 \\
Gala Supreme & 6 September & 20.9 & & 5 September & 21.7 \\
Shizuka & - & - & & 5 September & 21.7 \\
Orin & - & - & & 13 September & 16.3 \\
Yataka & 10 September & 22.9 & & 13 September & 16.3 \\
Cameo & - & - & & 14 September & 16.2 \\
Fuji & 14 September & 23.3 & & 18 September & 14.7 \\
Suncrisp & 20 September & 19.4 & 20 September & 15.4 \\
Braeburn & - & - & 14 September & 16.2 \\
Enterprise & 17 September & 21.1 & 20 September & 15.4 \\
GoldRush & 27 September & 20.6 & 5 October & 12.3 \\
\hline Z & & & &
\end{tabular}

${ }^{\mathrm{z}}$ Not inoculated in 1998. of fruit surface area affected. Severity in the laboratory was obtained from the mean of two measurements (length and width) from each lesion. Only symptomatic fruit were included in the calculation of mean wound severity. In the field, incidence and severity were determined at 1 week preharvest, harvest, and 1 week postharvest. In the laboratory, incidence and severity were evaluated at 1, 2, and 3 weeks postinoculation. Cultivar ranks at the various postinoculation times were used to calculate the mean rank.

Percent incidence data were transformed (arcsine transformation), followed by analysis of variance and means separation with the Waller-Duncan $k$-ratio $t$ test (SAS Institute, Cary, NC). Differences among categorical rankings for severity in the field were determined with the KruskalWallis test (SAS Institute, Cary, NC). For severity in the laboratory, the mean lesion diameter was subjected to analysis of variance and means separated with the WallerDuncan test. Final cultivar ranks were determined by averaging the mean ranks for the six sets of laboratory observations. The nonparametric Spearman rank correlation analysis was used to determine the relationships among the various measures and with harvest date, fruit firmness and percent of soluble solids (SAS Institute). Correlation analysis was used to measure the reproducibility of the cultivar mean ranks between the two growing seasons.

\section{RESULTS AND DISCUSSION}

Field experiments. At harvest, bitter rot incidence in 1998 ranged from 25\% for Ginger Gold to $95 \%$ for Golden Supreme (Table 2). Fuji and Ginger Gold had the lowest mean ranks for field incidence and Sunrise and Sansa had the highest mean ranks for field incidence in 1998 (Table 3). In 1999, incidence ranged from $36.2 \%$ for Enterprise, a scab-resistant cultivar, to $100 \%$ for Yataka and Suncrisp. Enterprise, Ginger Gold and Sansa had the lowest mean ranks for field incidence, and Yataka, Sunrise, and Pristine had the highest mean ranks for field incidence in 1999 (Table 3). Cultivar mean ranks for field disease incidence in 1998 were not correlated with those for $1999\left(r_{s}=0.08, P \leq 0.80\right)$, showing no repeatability for this measure of relative susceptibility.

Field disease severity in 1998 was lowest for Fuji and Creston, and highest for Sansa and Pristine (Table 2). Differences among highest and lowest were significant $\left(\chi^{2}=7.5, P \leq 0.05\right)$. Fuji and Enterprise had the lowest mean ranks for field severity, and Sansa and Sunrise had the highest mean ranks for field severity in 1998 (Table 3). In 1999, disease severity at harvest was lowest for Enterprise and highest for Sunrise and Yataka. Differences among highest and lowest were significant $\left(\chi^{2}=\right.$ $7.7, P \leq 0.05)$. Mean ranks for field severity in 1999 were lowest for Ginger Gold 
and Fuji, and highest for Sunrise and Yataka (Table 3). Cultivar ranks for field severity in 1998 were correlated with those in $1999\left(r_{s}=0.68, P=0.02\right)$, indicating moderate repeatability for this measure of relative susceptibility.

Disease incidence was correlated with disease severity in both years $\left(r_{s}=0.65, P\right.$ $=0.02$, and $r_{s}=0.65, P=0.01$ in 1998 and 1999, respectively). Neither disease incidence nor severity showed significant correlations with harvest date, soluble solids, or flesh firmness in either year. Temperatures in the field might have contributed to the variability of the field experiments between years; 1999 was approximately $2.1^{\circ} \mathrm{C}$ cooler than 1998 (Table 1). We thought that early-maturing cultivars might show higher susceptibility in the field experiments than later-maturing cultivars because of temperature differences between early August and late September. Temperatures in 1998 were relatively constant over the duration of the testing pe- riod, ranging from 19.4 to 26.1, compared to 1999 when temperatures ranged from 12.3 to 26.9 (Table 1). Increased sugar content is known to influence susceptibility of apple to white rot caused by Botryosphaeria dothidea (3), but not to the bitter rot pathogens. Apples are reported to be susceptible to the bitter rot pathogens at all stages of development $(8,11)$.

Laboratory experiments. In 1998, incidence ranged from $12.5 \%$ for Creston to $100 \%$ for Pristine. Fuji and Creston had the

Table 2. Disease incidence and severity on selected apple cultivars inoculated with Colletotrichum acutatum in 1998 and 1999

\begin{tabular}{|c|c|c|c|c|c|c|c|c|c|c|}
\hline \multirow[b]{2}{*}{ Cultivar } & \multicolumn{2}{|c|}{ Field incidence $(\%)^{\mathrm{u}}$} & \multicolumn{2}{|c|}{ Field severity rating } & \multicolumn{2}{|c|}{$\begin{array}{c}\text { Laboratory (nonwounded) } \\
\text { incidence }(\%)^{\mathbf{v}}\end{array}$} & \multicolumn{2}{|c|}{$\begin{array}{c}\text { Laboratory (nonwounded) } \\
\text { severity }(\mathbf{m m})^{\mathbf{v}}\end{array}$} & \multicolumn{2}{|c|}{$\begin{array}{c}\text { Laboratory (wounded) } \\
\text { severity }(\mathrm{mm})^{\mathrm{w}}\end{array}$} \\
\hline & 1998 & 1999 & 1998 & 1999 & 1998 & 1999 & 1998 & 1999 & 1998 & 1999 \\
\hline Arlet & $63.1 b^{x}$ & $70.8 \mathrm{bcd}$ & $1.0^{\mathrm{y}}$ & 1.0 & $87.5 \mathrm{ab}$ & $14.3 \mathrm{~d}-\mathrm{g}$ & $31.2 \mathrm{~d}$ & $32.2 \mathrm{ab}$ & $33.1 \mathrm{~cd}$ & $20.0 \mathrm{gh}$ \\
\hline Creston & $79.2 \mathrm{ab}$ & $65.3 \mathrm{cde}$ & 0.7 & 1.4 & $12.5 \mathrm{e}$ & $0.0 \mathrm{~g}$ & $1.7 \mathrm{f}$ & $0.0 \mathrm{c}$ & $36.0 \mathrm{c}$ & $28.1 \mathrm{def}$ \\
\hline Enterprise & $37.5 \mathrm{de}$ & $36.2 \mathrm{f}$ & 1.0 & 0.9 & 38.1 cde & $20.8 \mathrm{c}-\mathrm{g}$ & $10.2 \mathrm{ef}$ & $2.4 \mathrm{c}$ & $27.7 \mathrm{fg}$ & $30.0 \mathrm{de}$ \\
\hline Fortune & $-\mathrm{z}$ & 41.7 ef & - & 1.6 & - & $12.5 \mathrm{~d}-\mathrm{g}$ & - & $5.8 \mathrm{c}$ & - & $30.4 \mathrm{de}$ \\
\hline Fuji, B.C. No. 2 & $29.2 \mathrm{e}$ & $87.5 \mathrm{abc}$ & 1.0 & 1.0 & $20.8 \mathrm{de}$ & $0.0 \mathrm{~g}$ & $1.0 \mathrm{f}$ & $0.0 \mathrm{c}$ & $18.4 \mathrm{~h}$ & $13.5 \mathrm{ij}$ \\
\hline Gala Supreme & - & $82.8 \mathrm{abc}$ & - & 1.0 & - & $16.7 \mathrm{~d}-\mathrm{g}$ & - & $1.3 \mathrm{c}$ & - & $19.0 \mathrm{ghi}$ \\
\hline Ginger Gold & $25.0 \mathrm{e}$ & $50.0 \mathrm{def}$ & 1.0 & 1.0 & $82.7 \mathrm{ab}$ & $45.8 \mathrm{ab}$ & $15.0 \mathrm{e}$ & $1.0 \mathrm{c}$ & $39.4 \mathrm{~b}$ & $24.7 \mathrm{efg}$ \\
\hline Golden Delicious & $56.3 \mathrm{~cd}$ & $62.5 \mathrm{c}-\mathrm{f}$ & 1.0 & 1.0 & $27.0 \mathrm{de}$ & $0.0 \mathrm{~g}$ & $1.0 \mathrm{f}$ & $2.3 \mathrm{c}$ & $31.0 \mathrm{de}$ & $24.5 \mathrm{fgh}$ \\
\hline Golden Supreme & $95.0 \mathrm{a}$ & $87.0 \mathrm{abc}$ & 1.1 & 1.4 & $45.8 \mathrm{~cd}$ & $25.0 \mathrm{~b}-\mathrm{f}$ & $40.0 \mathrm{bcd}$ & $1.1 \mathrm{c}$ & $26.5 \mathrm{~g}$ & $18.6 \mathrm{hi}$ \\
\hline GoldRush & - & $87.5 \mathrm{abc}$ & & 1.2 & $74.2 \mathrm{ab}$ & $16.7 \mathrm{~d}-\mathrm{g}$ & 8.5 ef & $1.8 \mathrm{c}$ & $19.8 \mathrm{~h}$ & $8.7 \mathrm{j}$ \\
\hline Honeycrisp & - & $83.3 \mathrm{abc}$ & & 1.2 & $79.2 \mathrm{ab}$ & $4.2 \mathrm{fg}$ & $32.5 \mathrm{~d}$ & $18.3 \mathrm{abc}$ & $50.8 \mathrm{a}$ & $33.8 \mathrm{~cd}$ \\
\hline PioneerMac & $54.2 \mathrm{~cd}$ & $50.0 \mathrm{def}$ & 1.1 & 1.0 & $29.2 \mathrm{de}$ & $34.8 \mathrm{a}-\mathrm{d}$ & $61.3 \mathrm{a}$ & $35.0 \mathrm{ab}$ & $29.1 \mathrm{efg}$ & $21.9 \mathrm{gh}$ \\
\hline Pristine & $27.5 \mathrm{e}$ & $95.8 \mathrm{ab}$ & 1.9 & 1.1 & $100.0 \mathrm{a}$ & $43.0 \mathrm{abc}$ & $43.0 \mathrm{bc}$ & $37.1 \mathrm{a}$ & $39.4 \mathrm{~b}$ & $45.9 \mathrm{a}$ \\
\hline Sansa & $91.7 \mathrm{a}$ & $62.5 \mathrm{c}-\mathrm{f}$ & 1.6 & 1.6 & $33.3 \mathrm{de}$ & $9.8 \mathrm{efg}$ & $33.8 \mathrm{~cd}$ & $9.8 \mathrm{bc}$ & $42.1 \mathrm{~b}$ & $40.7 \mathrm{ab}$ \\
\hline Senshu & - & $83.3 \mathrm{abc}$ & - & 1.0 & - & $4.7 \mathrm{fg}$ & - & $0.7 \mathrm{c}$ & - & $19.2 \mathrm{ghi}$ \\
\hline Suncrisp & - & $100.0 \mathrm{a}$ & - & 1.4 & - & $56.5 \mathrm{a}$ & - & $11.9 \mathrm{abc}$ & - & $18.8 \mathrm{ghi}$ \\
\hline Sunrise & $82.1 \mathrm{ab}$ & $95.8 \mathrm{ab}$ & 1.1 & 2.1 & $63.0 \mathrm{bc}$ & 29.2 b-e & $13.9 \mathrm{e}$ & $12.2 \mathrm{abc}$ & $17.6 \mathrm{~h}$ & $36.9 \mathrm{bc}$ \\
\hline Yataka & $67.1 \mathrm{bc}$ & $100.0 \mathrm{a}$ & 1.0 & 2.0 & $39.0 \mathrm{~cd}$ & $12.5 \mathrm{~d}-\mathrm{g}$ & $49.8 \mathrm{~b}$ & $16.5 \mathrm{abc}$ & 29.7 ef & $31.9 \mathrm{~cd}$ \\
\hline
\end{tabular}

u Field incidence and severity data are from the harvest assessment for both years.

v Laboratory incidence and severity data (nonwounded fruit) are from the assessment at 3 and 4 weeks post-inoculation in 1998 and 1999 , respectively.

w Laboratory severity data (wounded fruit) are from lesions assessed at 2 weeks postinoculation.

$x$ Data are the mean of 24 observations from three replicates of eight fruit. Different letters denote significant differences among means according to the Waller-Duncan test $(P \leq 0.05)$.

y Fruit surface area affected rated on a scale of 0 to 6 , with $0=$ no lesions, $1=1$ to $10 \%, 2=11$ to $25 \%, 3=26$ to $50 \%, 4=51$ to $75 \%, 5=76$ to $90 \%$, and $6=91$ to $100 \%$ of fruit surface area affected. Differences among categorical rankings were determined with the Kruskal-Wallis chi-square test. $\chi^{2}=7.5$, $P \leq 0.05$, and $\chi^{2}=7.7, P \leq 0.05$ in 1998 and 1999 , respectively.

z Fruit not available.

Table 3. Mean ranks for field and laboratory disease incidence and severity of selected apple cultivars inoculated with Colletotrichum acutatum in 1998 and 1999, listed from least to most susceptible based on combined mean laboratory ranks

\begin{tabular}{|c|c|c|c|c|c|c|c|c|c|c|c|}
\hline \multirow[b]{2}{*}{ Cultivar } & \multirow{2}{*}{$\begin{array}{l}\text { Harvest } \\
\text { date rank }\end{array}$} & \multicolumn{2}{|c|}{ Field incidence $(\%)$} & \multicolumn{2}{|c|}{ Field severity rating } & \multicolumn{2}{|c|}{$\begin{array}{c}\text { Laboratory } \\
\text { (nonwounded) } \\
\text { incidence }(\%)\end{array}$} & \multicolumn{2}{|c|}{$\begin{array}{c}\text { Laboratory (non- } \\
\text { wounded) } \\
\text { severity (mm) } \\
\end{array}$} & \multicolumn{2}{|c|}{$\begin{array}{c}\text { Laboratory } \\
\text { (wounded) sever- } \\
\text { ity }(\mathbf{m m})\end{array}$} \\
\hline & & 1998 & 1999 & 1998 & 1999 & 1998 & 1999 & 1998 & 1999 & 1998 & 1999 \\
\hline Fuji, B.C. No. 2 & $12^{\mathrm{x}}$ & $2.6^{\mathrm{y}}$ & 8.1 & 3.3 & 4.0 & 2.0 & 3.3 & 2.3 & 3.1 & 4.3 & 2.0 \\
\hline Creston & 10 & 7.8 & 5.5 & 7.5 & 7.6 & 2.0 & 3.3 & 2.9 & 3.1 & 5.8 & 7.7 \\
\hline Golden Delicious & 9 & 5.4 & 4.1 & 4.5 & 4.5 & 2.8 & 3.9 & 1.6 & 4.4 & 9.0 & 6.3 \\
\hline GoldRush & 14 & $-{ }^{z}$ & 9.6 & - & 7.1 & 12.0 & 6.5 & 6.0 & 4.6 & 3.2 & 1.0 \\
\hline PioneerMac & 5 & 4.6 & 4.5 & 6.3 & 5.3 & 3.8 & 8.9 & 6.8 & 8.0 & 4.3 & 4.3 \\
\hline Golden Supreme & 7 & 4.0 & 8.9 & 6.1 & 10.3 & 9.3 & 6.4 & 8.9 & 6.9 & 3.3 & 3.4 \\
\hline Sunrise & 2 & 10.8 & 12.6 & 8.8 & 13.4 & 5.8 & 8.1 & 4.3 & 7.5 & 2.0 & 13.3 \\
\hline Enterprise & 13 & 4.9 & 2.5 & 4.1 & 4.4 & 5.9 & 8.6 & 6.6 & 6.5 & 6.7 & 9.0 \\
\hline Arlet & 6 & 8.5 & 6.5 & 6.6 & 4.8 & 13.3 & 7.4 & 10.8 & 10.6 & 9.3 & 4.0 \\
\hline Sansa & 3 & 9.8 & 3.5 & 8.9 & 10.1 & 7.3 & 9.0 & 12.0 & 7.9 & 10.7 & 12.3 \\
\hline Yataka & 11 & 6.3 & 13.9 & 5.6 & 12.5 & 7.5 & 9.4 & 11.0 & 11.8 & 7.3 & 8.7 \\
\hline Honeycrisp & 8 & - & 9.3 & - & 9.4 & 11.8 & 4.1 & 13.0 & 7.3 & 14.0 & 10.3 \\
\hline Ginger Gold & 4 & 3.3 & 3.5 & 4.9 & 2.9 & 10.1 & 13.4 & 8.4 & 8.5 & 11.5 & 9.0 \\
\hline Pristine & 1 & 4.3 & 12.5 & 8.3 & 8.4 & 10.8 & 12.9 & 9.8 & 13.3 & 10.1 & 13.3 \\
\hline
\end{tabular}

$\mathrm{x}$ Harvest date rank is from earliest $=1$ to latest $=14$. Cultivars are arranged from least susceptible to most susceptible based on the laboratory tests with nonwounded fruit.

y Data are the mean ranks from 3 sets of sequential observations (field incidence [percent fruit infected] and severity [0 to 6 scale of surface area affected] were determined at 1 week preharvest, harvest, and 2 weeks postharvest; laboratory incidence [percent fruit infected] and severity [mean lesion diameter] were evaluated at 1,2, and 3 weeks postinoculation). A higher rank indicates higher levels of disease incidence and severity.

z Fruit not available. 
lowest mean ranks for incidence on nonwounded fruit in both 1998 and 1999 (Table 3). Incidence in 1999 ranged from 0\% for Creston, Golden Delicious, and Fuji to $56.5 \%$ for Suncrisp (Table 2). Cultivar ranks for disease incidence in the laboratory in 1998 were correlated with those for $1999\left(r_{s}=0.60, P=0.03\right)$, showing moderate repeatability for this measure of relative susceptibility.

Disease severity after 2 weeks at nonwound inoculations was lowest for Golden Delicious and Fuji and highest for Pioneer Mac in 1998 (Table 2). Mean ranks over the postinoculation period were lowest for Golden Delicious and Fuji and highest for Honeycrisp and Sansa (Table 3). In 1999, disease severity on nonwounded fruit was lowest for Fuji and Creston and highest for Pioneer Mac (Table 2). Mean ranks over the postinoculation period were lowest for Creston and Fuji and highest for Pristine and Yataka (Table 3). Cultivar ranks for disease severity in nonwounded fruit in 1998 were correlated with those of $1999\left(r_{s}\right.$ $=0.70, P=0.005$ ), showing high repeatability for this measure of relative susceptibility. Disease incidence was correlated with disease severity in both years $\left(r_{s}=\right.$ $0.74, P=0.002$, and $r_{s}=0.84, P=0.0001$ in 1998 and 1999, respectively).

Sunrise and Fuji exhibited the smallest lesions at wounds, and Honeycrisp had the largest lesions in 1998 (Table 2). Sunrise and GoldRush had the lowest mean ranks in 1998, whereas Honeycrisp and Ginger Gold had the highest mean ranks (Table 3 ). In 1999, the smallest lesions at wounds occurred on GoldRush and Fuji, and the largest lesions occurred on Pristine and Sansa (Table 2). GoldRush and Fuji had the lowest mean ranks in 1999, whereas Pristine and Sunrise had the highest mean ranks (Table 3). Cultivar ranks for disease severity at wounds in 1998 were correlated with those for $1999\left(r_{s}=0.46, P=0.10\right)$, showing low repeatability for this measure of relative susceptibility. There were no correlations in either year between harvest date, soluble solids, or flesh firmness, and any of the laboratory measures of relative susceptibility.

Field severity was not correlated with laboratory severity (wounded or non- wounded fruit) in either year $\left(r_{s}=0.46, P\right.$ $=0.13$; and $r_{s}=0.08, P=0.80$ in 1998 and 1999 , respectively). The laboratory severity ranks for wounded and nonwounded fruit were correlated in $1998\left(r_{s}=0.59, P\right.$ $=0.03)$, but not in $1999\left(r_{s}=0.44, P=\right.$ 0.12 ). The tests with the best reproducibility were the laboratory tests with nonwounded, detached fruit inoculated with conidia in tubes attached to the fruit surface with modeling clay. This is a laborintensive process, but provided consistent results over the 2-year study period. For evaluating relative susceptibility of fruit to bitter rot, either incidence or severity could be recorded because these variables were significantly correlated in both years.

Other factors may influence the relative susceptibility of apple cultivars to the bitter rot pathogens. For example, differences in amounts of overwintering inoculum from mummies or twig cankers could be an important element of perceived susceptibility in the orchard. Insect feeding preferences that might vary among cultivars also could influence perceived susceptibility by creating potential infection courts. Also, early-maturing cultivars could escape the larger amount of inoculum that occurs later in the growing season. The present study is limited because only one isolate of $\mathrm{C}$. $\mathrm{acu}$ tatum was used for the inoculation tests. Field populations of $C$. acutatum and $C$. gloeosporioides would be expected to vary in virulence; however, there are no reports of cultivar specificity with either pathogen on apple.

Based on the combined laboratory data from 2 years of study, we classified the cultivars into four relative susceptibility groups: most susceptible: Pristine, Honeycrisp, and Ginger Gold; highly susceptible: Yataka, Sansa, Arlet, and Enterprise; moderately susceptible: Sunrise, Golden Supreme, PioneerMac, GoldRush, Golden Delicious, and Creston; and least susceptible: Fuji. Previous published rankings have included Fuji and Golden Delicious among the most susceptible cultivars to bitter rot (7). Although McVay et al. (7) based their cultivar rankings on field observations and did not distinguish between the two bitter rot pathogens, their observations and the results of the present study indicate that new apple cultivars from the first NE-183 planting show no improvement in resistance to $C$. acutatum.

\section{ACKNOWLEDGMENTS}

We thank V. L. Crim and R. D. Young for technical assistance.

\section{LITERATURE CITED}

1. Anderson, H. W. 1956. Diseases of Fruit Crops. McGraw-Hill, New York.

2. Bernstein, B., Zehr, E. I., Dean, R. A., and Shabi, E. 1995. Characteristics of Colletotrichum from peach, apple, pecan, and other hosts. Plant Dis. 79:478-482.

3. Kohn, F. C., and Hendrix, F. F. 1983. Influence of sugar content and $\mathrm{pH}$ on development of white rot on apples. Plant Dis. 67:410-412.

4. Jones, A. L., Biggs, A.R., Kiyomoto, R. K ., McNew, R., Rosenberger, D. A., and Yoder, K. S. 1998. Susceptibility of apple cultivars in the NE-183 project trial to apple scab, 1997. Biol. Cult. Tests Control Plant Dis. 13:35.

5. Jones, A. L. and Sutton, T. B. 1996. Diseases of tree fruits in the east. Mich. Agric. Exp. Stn. Publ. NCR-45.

6. Kiyomoto, R. K., Biggs, A.R., McNew, R., Rosenberger, D. A., and Yoder, K. S. 1998 Foliage susceptibility of 23 apple cultivars in the NE-183 project trial to cedar-apple rust, powdery mildew, and leaf spots, 1997. Biol. Cult. Tests Control Plant Dis. 13:36.

7. McVay, J. R., Walgenbach, J. F., Sikora, E. J., and Sutton, T. B. 1993. A Grower's Guide to Apple Insects and Diseases in the Southeast. Alabama Cooperative Extension Service, Auburn University, Circular ANR-838.

8. Noe, J. P. and Starkey, T. E. 1982. Relationship of apple fruit maturity and inoculum concentration to infection by Glomerella cingulata. Plant Dis. 66:379-381.

9. Roberts, J. W. and Pierce, L. 1935. Apple bitter rot and its control. USDA Farmers' Bul No. 938 .

10. Rosenberger, D. A., Yoder, K. S., Biggs, A R., Kiyomoto, R. K., and McNew, R. 1996 Comparative susceptibility of 23 apple cultivars in the NE-183 trial to powdery mildew and cedar apple rust, 1995. Biol. Cult. Tests Control Plant Dis. 11:36.

11. Shane, W. W., and Sutton, T. B. 1981. Germination, appressorium formation, and infection of immature and mature apple fruit by Glomerella cingulata. Phytopathology 71:454-457.

12. Yoder, K. S., Biggs, A. R., Kiyomoto, R. K., McNew, R., and Rosenberger D.A. 1997. Foliage susceptibility of 23 apple cultivars in the NE-183 trial to scab, powdery mildew, cedar apple rust, and leaf spot, 1996. Biol. Cult. Tests Control Plant Dis. 12:42-43. 